\title{
New essence of architectural skins: A comparative study between parametric and
ordinary designed buildings
}

\author{
Aako Noory M.Shari* and Amjad Muhammed Ali \\ Department of Architecture, College of Engineering, University of Sulaimani, Sulaymaniyah, Iraq. \\ *Corresponding Author: ako.mohamad@univsul.edu.iq
}

$\begin{array}{ll}\text { Submitted } & : 30 / 04 / 2020 \\ \text { Revised } & : 27 / 03 / 2021 \\ \text { Accepted } & : 18 / 05 / 2021\end{array}$

\begin{abstract}
This study discusses architectural skins in buildings with parametric design to verify whether they have specific and clear limitations with the other surfaces. This is an important characteristic of the essence of the architectural skins in buildings designed in ordinary ways, or whether there is ambiguity in that, and it is not easy to distinguish between the components of the architectural form of those buildings. The purpose of this study is to explore whether the new technology, represented by parametric design, makes the architectural skins of buildings lose their leadership of other components in the composition and presentation of the architectural form of the buildings, to allow the emergence of new essences for architectural skins of buildings with parametric design. This process will be based on a comparative study between buildings designed in ordinary ways and buildings designed with parametric design, to examine whether technology has changed architectural skins and made them lose part of their essence and role, by comparing them with the basic components of architectural skins essence.
\end{abstract}

Keywords: Architectural form; Architectural skin; Essence; Parametric Design; Technology.

\section{INTRODUCTION}

Architectural skin is the physical separator between the interior and exterior of the building which is surrounded by walls, floors, roofs, fenestrations, and doors (Emily Nonko, 2016). This research is focusing just on the vertical skin or the architectural façade which is the front elevation of a building (Milnes, 1994). It is clear that the impact of technology on architecture can be seen, as a product or as a type of technology, as it brings challenges to architecture.

Architecture programs, for example, are attempts to overcome this challenge. Since postmodernism, the world has witnessed increasing trends in building facades. Consequently, the interface design accommodates an important role in architectural practice partly due to the support of digital technologies (Pell, 2010). Most computer aided design (CAD) programs are a form of imagination, but there is a new generation of parametric modeling software that transforms CAD from a fantasy tool into a powerful and flexible simulation tool called parametric, which changes the way people think about design (Zarei, 2012) Parametric engineering modeling is a field study algorithms that 
calculate engineering (Kelly, 2013) and explore alternative models efficiently without the need for manual creation of each different version of the design model for each scenario (Gallas, 2015). In fact, it is the only parameter that has permeated the vocabulary of digital architects to such an extent that it has become a model term for integrated digital transformation in architecture (Schumacher, 2016). The Oxford Dictionary defines parameter as a numerical or other measurable factor forming one of a set that defines a system or sets the conditions of its operation, or as a limit which defines the scope of a particular process or activity, and the word parametric as relating to or expressed in terms of a parameter or parameters (Caetano, 2020). The transformation of architectural design practices has been underway for almost forty years, given the development and democratization of computer technology. Since then, architects have been continuously confronted with digital challenges, among those, the implementation of parametric modeling tools (Stals, 2021). Parametric design techniques offer obvious advantages for engineering and manufacturing processes. Now, architects emerge to apply these methods in their creation of design suggesting solutions at an earlier stage of the process. Through the coupling of architectural design with parametric modeling methods, this allows a deeper comprehension of the design objectives and aids designers in their decisions to find solutions (Schnabel, 2007) The progress of programs in architecture has been relatively slow, because most of the construction projects are unique and need to involve different groups of professionals who use different software packages that are difficult to standardize (Graham, 2012). Among that, a facade segmentation framework is modeled in a hierarchy by 2D images of a rectangular area of a contour of facades (Sharon, 2016). Yet, still there are many obstacles when attempting to exchange complex three-dimensional digital data, including the lack of a standard data exchange format (Schodek, 2005). A major barrier concerns the level of effort necessary to implement the algorithms: the task is that, for most, the tool needs only to be adequate to it (Woodbury, 2010). Parametric elements also interfere with software packages primarily dealing with animation or simulation of physical environments, such as Autodesk (Bottazzi, 2018), while modern technologies allow design exploration to go beyond traditional capabilities, thus encouraging the development and spread of complex shapes, new patterns, and advanced production techniques. Fortunately, computer does not destroy the human imagination, but it extends its potential borders and provides the means to explore experiment and investigate a better alternative world (Terzidis, 2003).

\section{PROBLEM}

This study is considering that the architectural skin has a certain essence, as previous studies talked about in this field, and it can be observed in human daily life that one of the main characteristics of architectural skins essence is having a clear limitations boundaries with other surfaces, which involved in creating the architectural form such as floors and other vertical surfaces.

The architectural skin plays a great roll in forming and presenting the architectural form with clear boundaries of its components.

Using the parametric method in design leads to ambiguity limitations between surfaces, and it may lead to changes in design procedure and cause the skin to lose its leading role in the design process. This change means change in the architectural skins essence and emergence of new ones with different properties and roles.

\section{RESEARCH METHOD}

The research depends on a comparative study between 10 samples of building skins with parametric design as shown in Figures 1-10, with the same number of skin examples designed in ordinary way as shown in Figures 11-20. The samples are selective ones chosen in order to verify if there is ambiguity or clearness in the joints of the architectural skin with the other surfaces, which means changes in the essence of architectural skin or constancy. 
The objective is to obtain the ratio of ambiguity in boundary limitations of each skin with the other jointed surfaces and to consider the high ratio, an indicator of losing a great part of skin essence.

Table 1 represents the measuring of the ratio of ambiguity limitation (A.L.), while the skin limitations of samples with each surface range from 0 to 2 , where 0 means no ambiguity or it has a clear boundary limitation, 1 means medium grade of ambiguity, and 2 means high grade of ambiguity.

The research found the summation of (A.L.) for each sample by collecting (horizontally) the values of limitation with the other three surfaces. It means that it can get the grade of each certain sample in total of 9. And by collecting summation A.L. (vertically), it can get the summation of all parametric samples (P.) or ordinary samples (O.).

That easily led us to get the ratio of ambiguity in boundary limitations for all the samples in the same column by collecting them vertically and calculating the ratio. On the other hand, it can get the ratio of ambiguity in boundary limitations with any certain surface, lower floor, for example, for all P. or O. samples by collecting their values vertically for each column and calculating the ratio.

\section{CASE STUDY}

The research represents 10 examples (Fig.1-Fig.10) of buildings designed with parametric. At the same time, it represents 10 other examples (Fig.11- Fig.20) of buildings designed ordinary and compares them in order to get the grade of change in their boundary's ambiguity or clearness in each one. However, the comparison is not between any two specific buildings. Yet, it tried to select the same type of buildings in the same sequence for each group (e.g.,111 or 2-12) and so on.

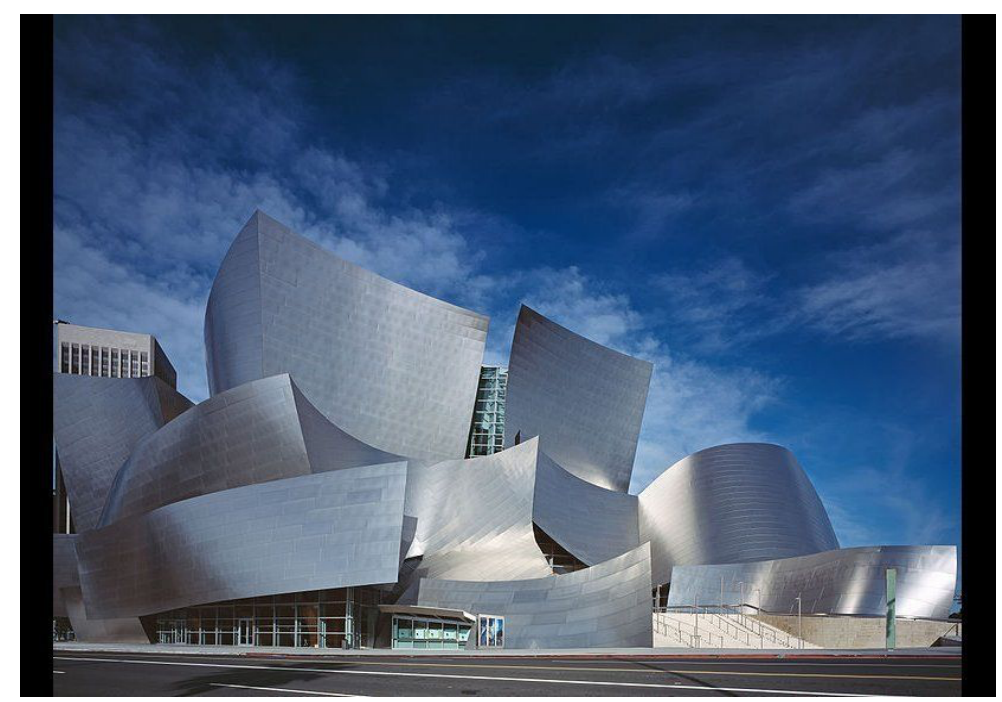

Figure 1. Walt Disney Concert Hall by Frank O. Gehry \& Partners, Los Angeles, USA. (https://www.huffpost.com/entry/top-10-buildingsparametr_b_838268?slideshow=true\#gallery/5bb2992fe4b0171db6a35006/0) 


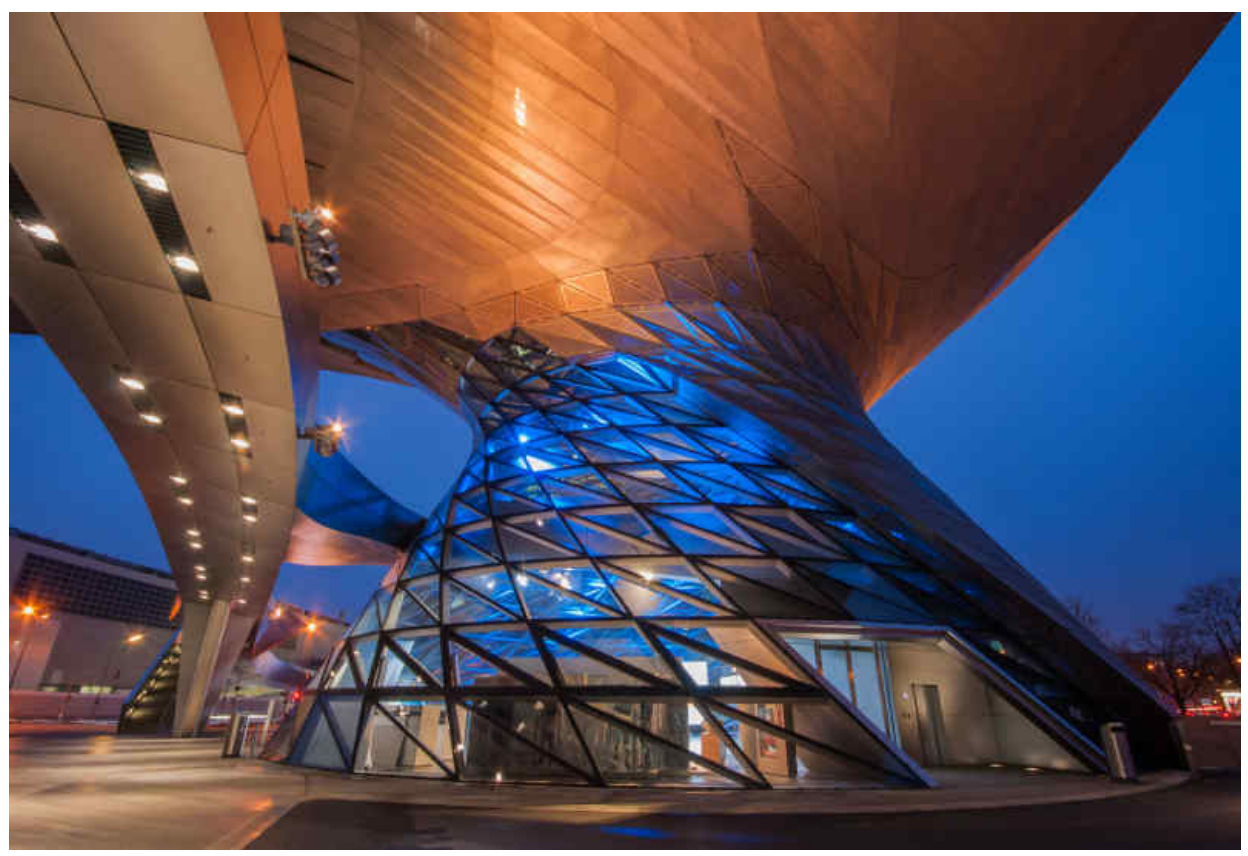

Figure 2. BMW Welt by Coop Himmleb in Munich, Germany. (https://www.greatvaluevacations.com/travel-inspiration/free-things-to-do-in-munich)

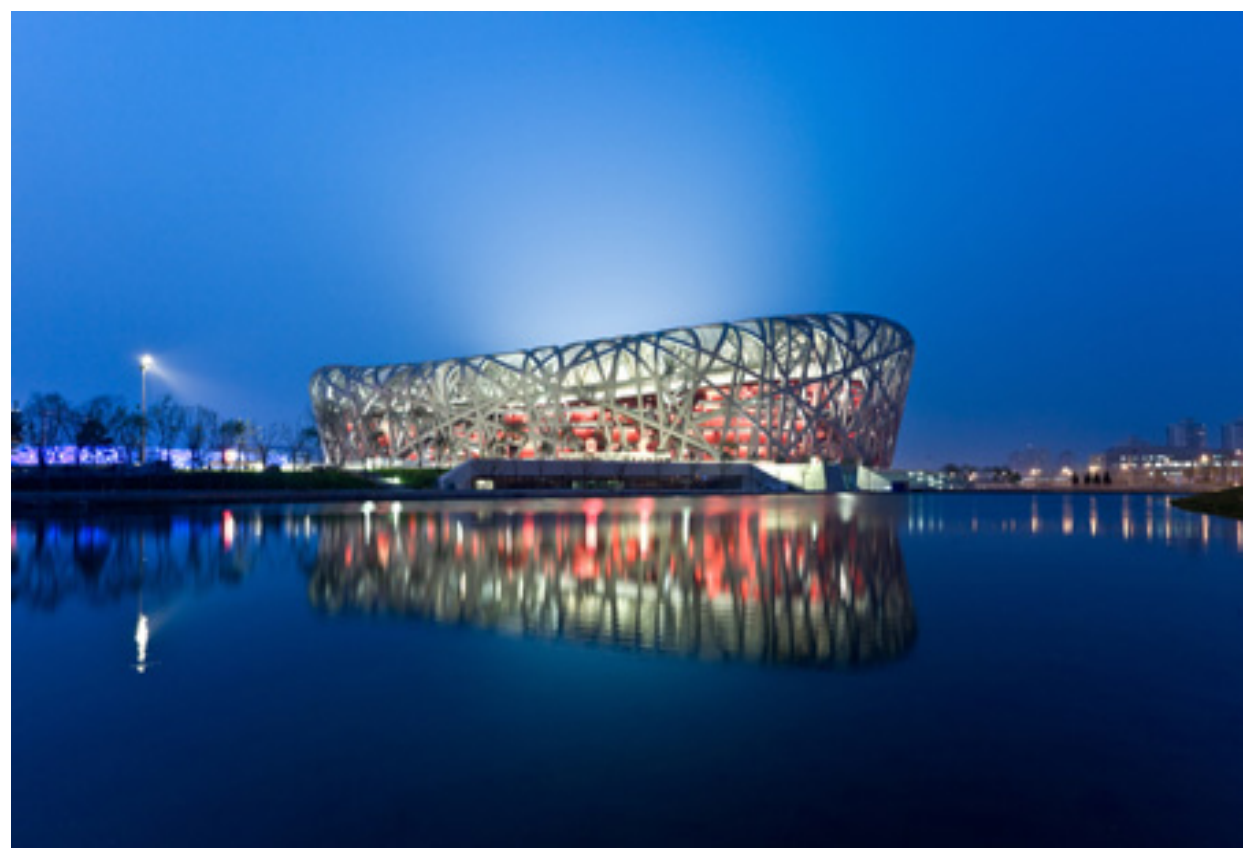

Figure 3. Beijing National Stadium by Herzog \& de Meuron, Beijing, China. (https://www.dezeen.com/2008/07/30/national-stadium-beijing-by-herzog-de-meuron/) 


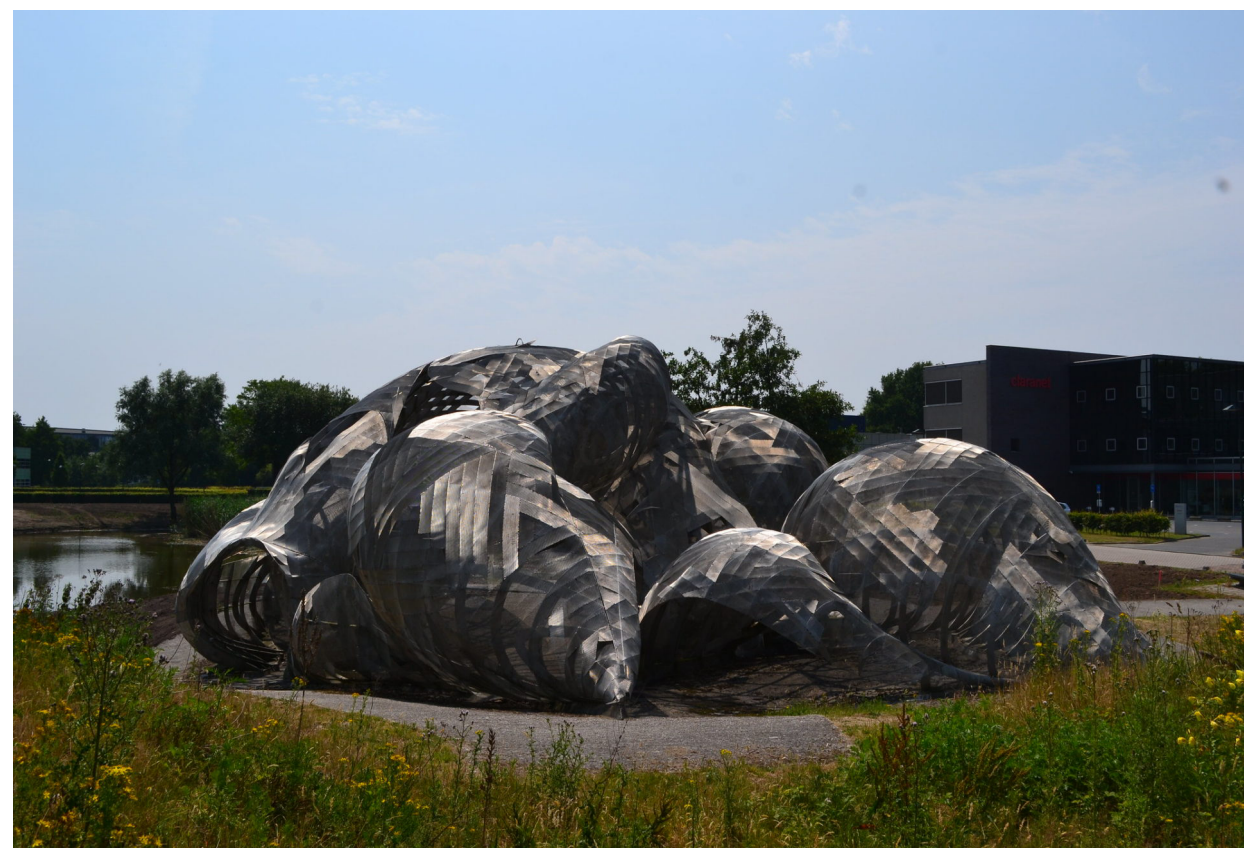

Figure 4. Son-O-House by NOX, Son en Bruegel, The Netherlands. (https://www.archined.nl/content/uploads/2004/05/nox-son-o-house-paradasos-1920x1280.jpg)

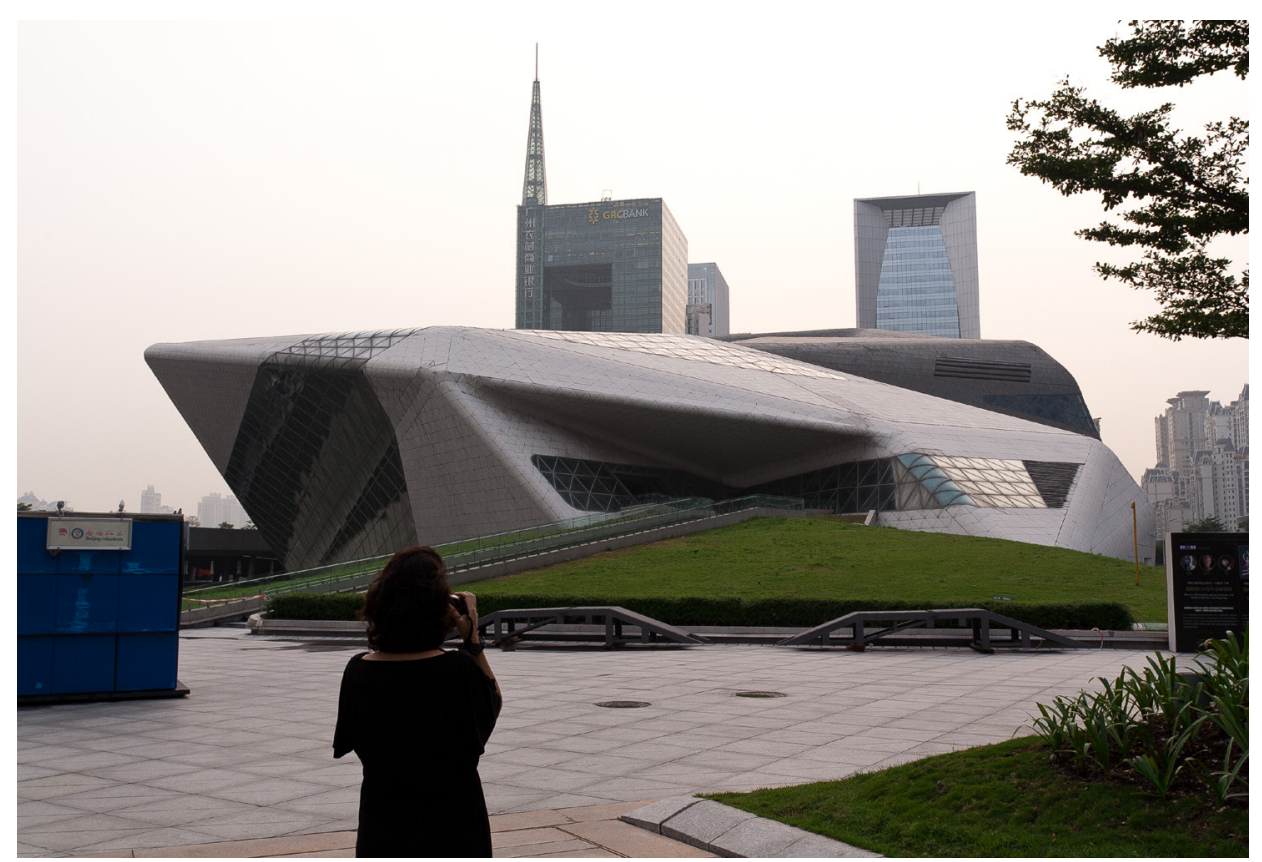

Figure 5. Gunagzhou Opera by Zaha Hadid Architects, Guangzhou, China. (http://arkitekt-ur.blogspot.com/2014/02/guangzhou-opera-house-by-zaha-hadid.html) 


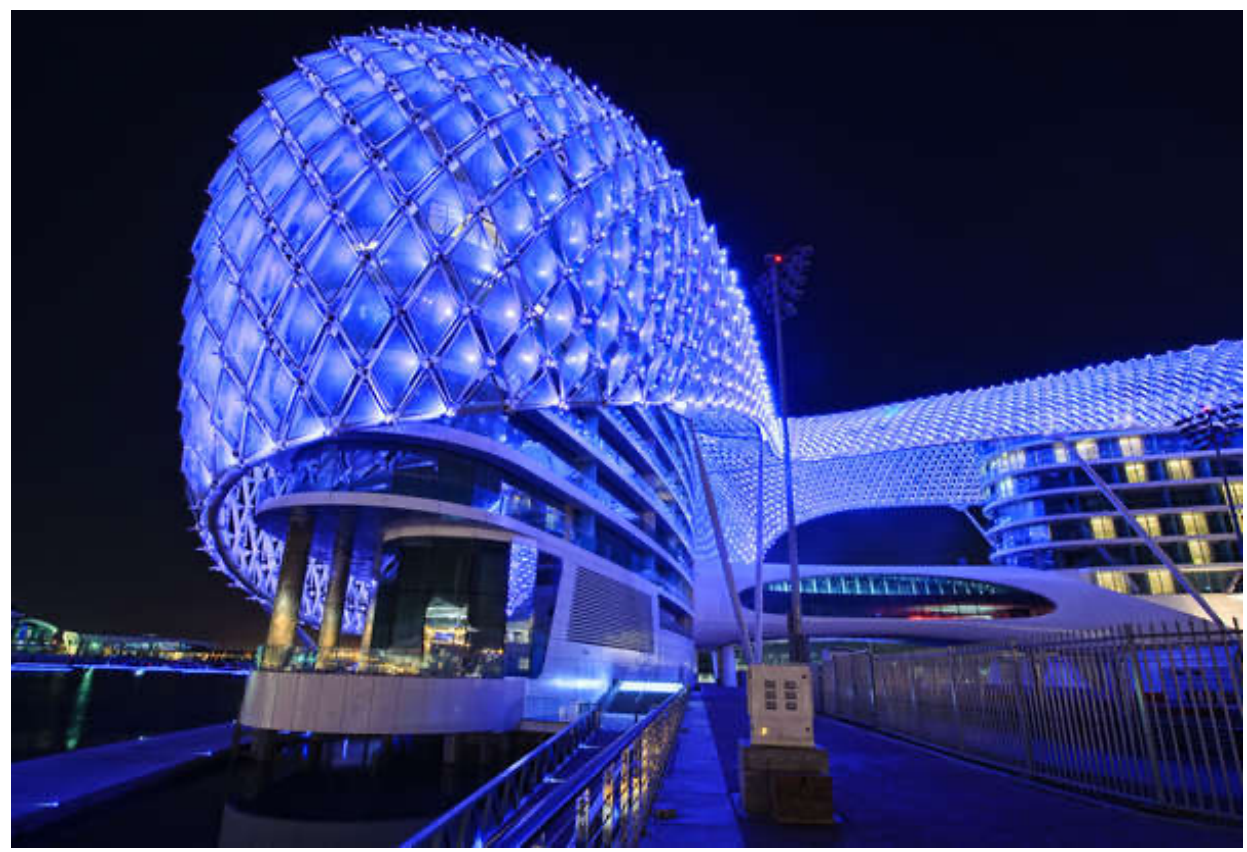

Figure 6.Yas Hotel by Asymptote in Abu Dhabi, UAE. (https://i1.wp.com/www10.aeccafe.com/blogs/arch-showcase/files/2011/06/YAS_Photos_A-List_Building4.jpg)

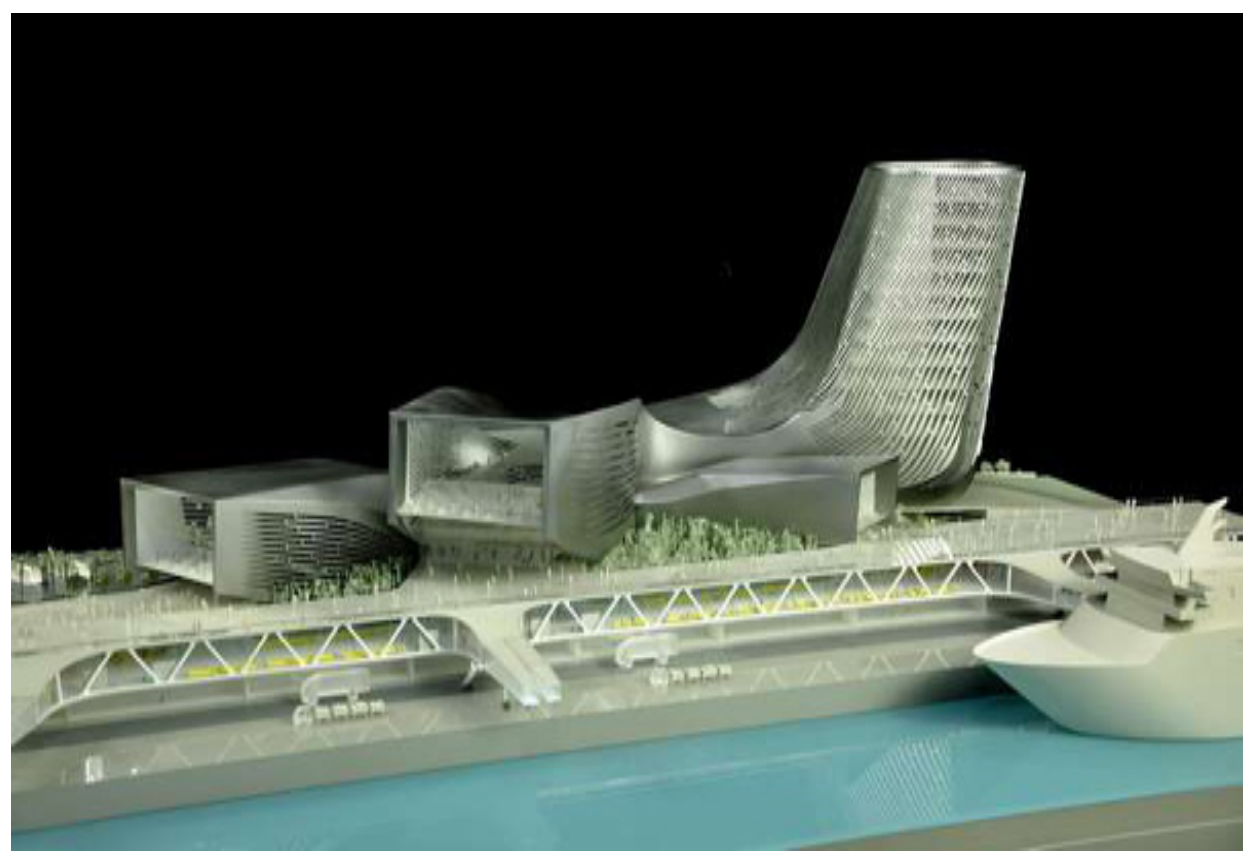

Figure 7. Kaohsiung Port and Cruise Service Center by Reiser Umemoto in Kaohsiung City, Taiwan. (https://i0.wp.com/www10.aeccafe.com/blogs/arch-showcase/files/2011/03/1111111111111111111111.jpg 0) 


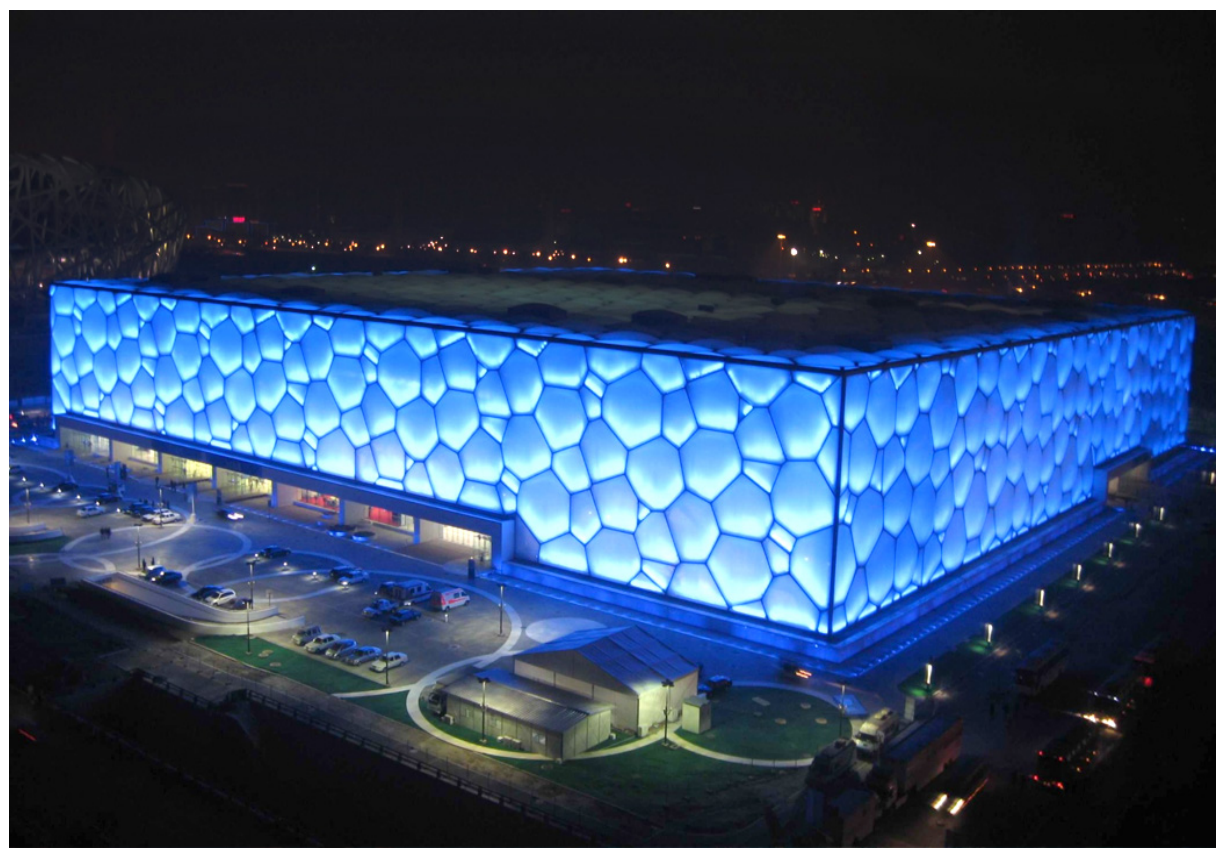

Figure 8. Beijing National Aquatics Center (Water Cube), by PTW Architects, CSCEC, CCDI, and Arup, Beijing, China.

(http://bubblemania.fr/wp-content/uploads/Happy-Magic-Water-Cube-Beijing-China-2.jpg)

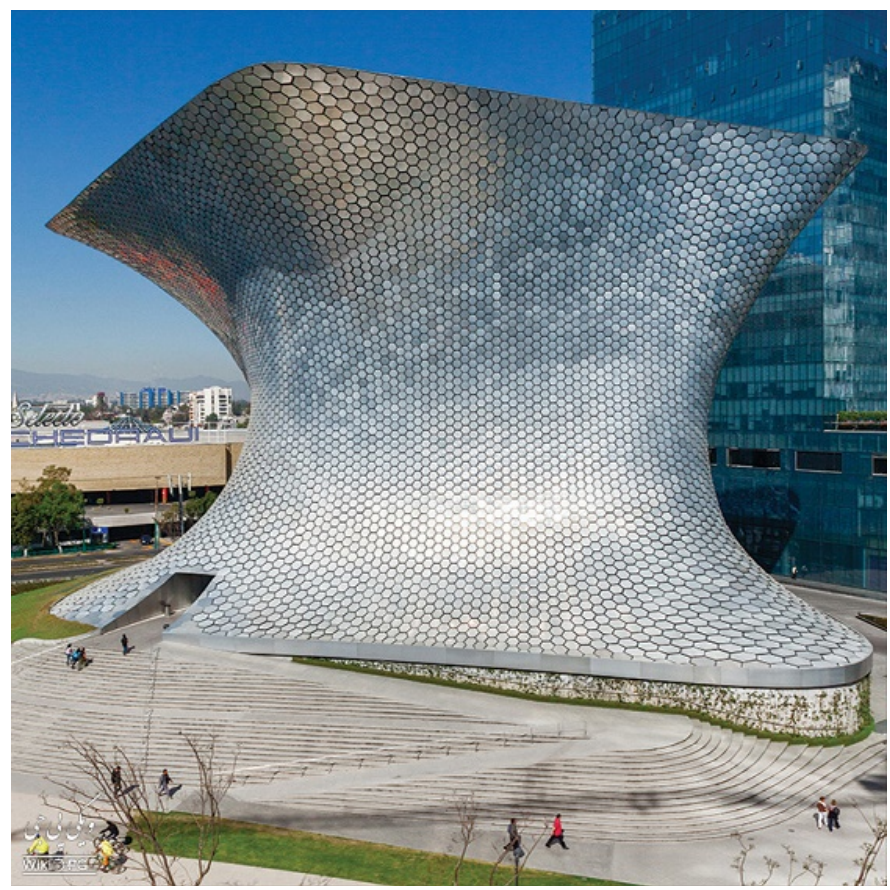

Figure 9. Museum Soumaya by Fernando Romero \& Nuevo Polanco, Mexico City. (http://iraneconomist.com/files/fa/news/1396/1/31/398250_748.jpg) 


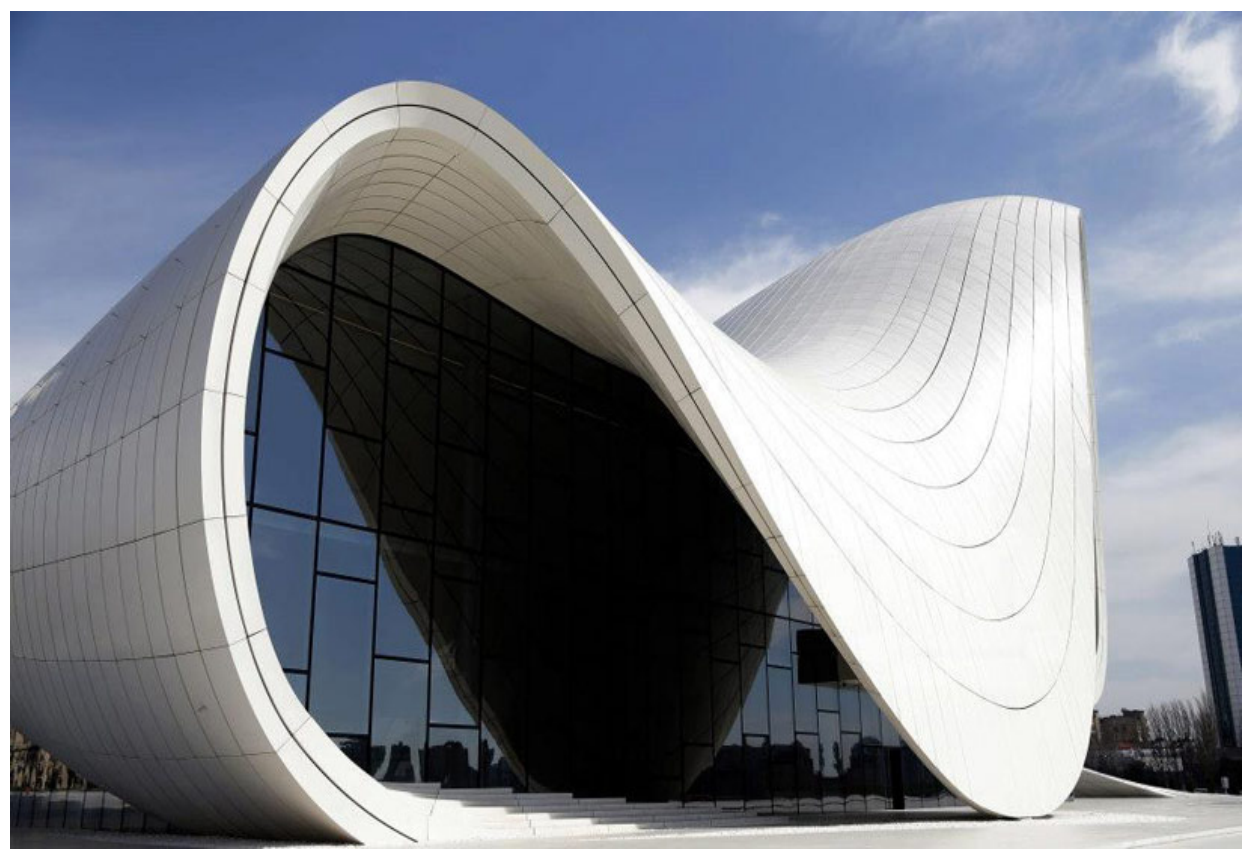

Figure 10. Heydar Aliyev Center by Zaha Hadid, Azerbaijan. (http://siuarchitecture.blogspot.com/2016/03/parametric-design.html)

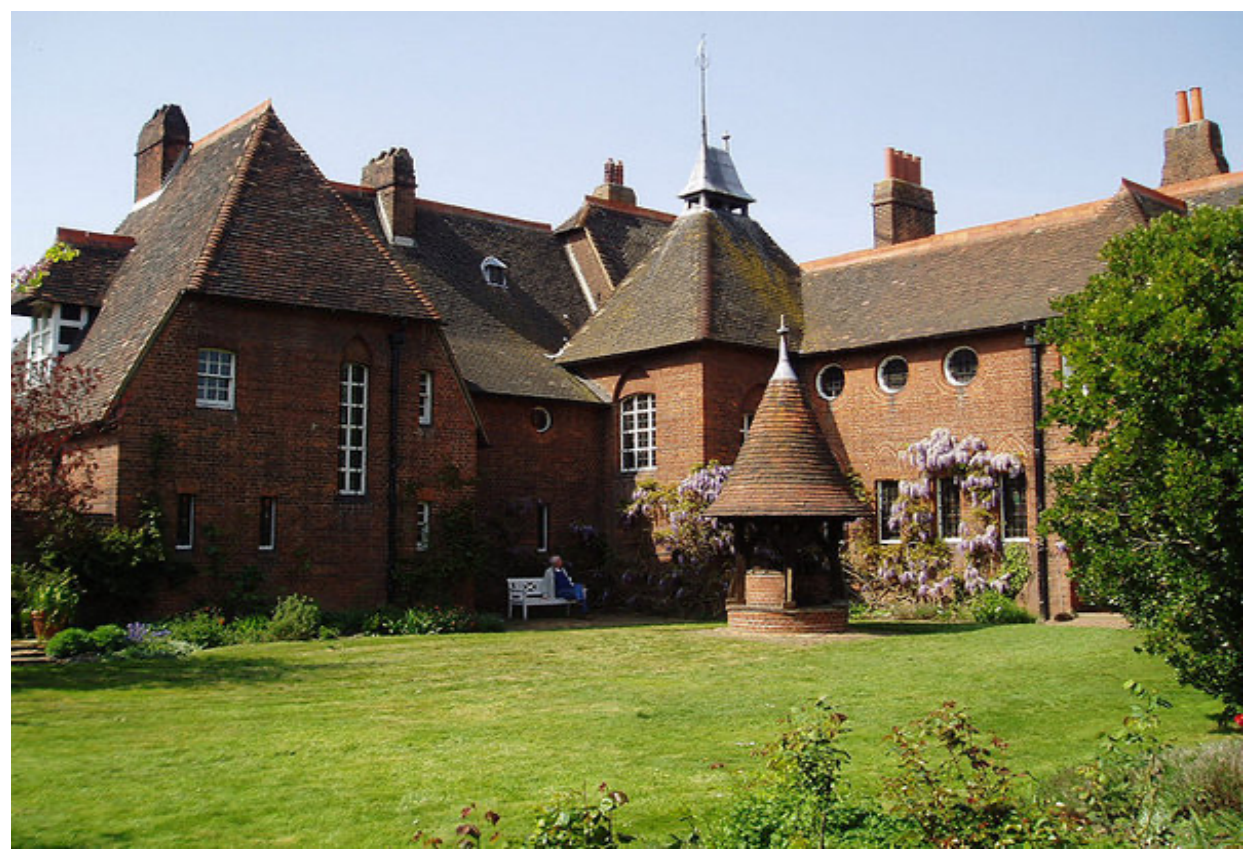

Figure 11. Red House by William Morris and Philip Webb, Bexleyheath, England. (https://smarthistory.org/william-morris-and-philip-webb-red-house/) 


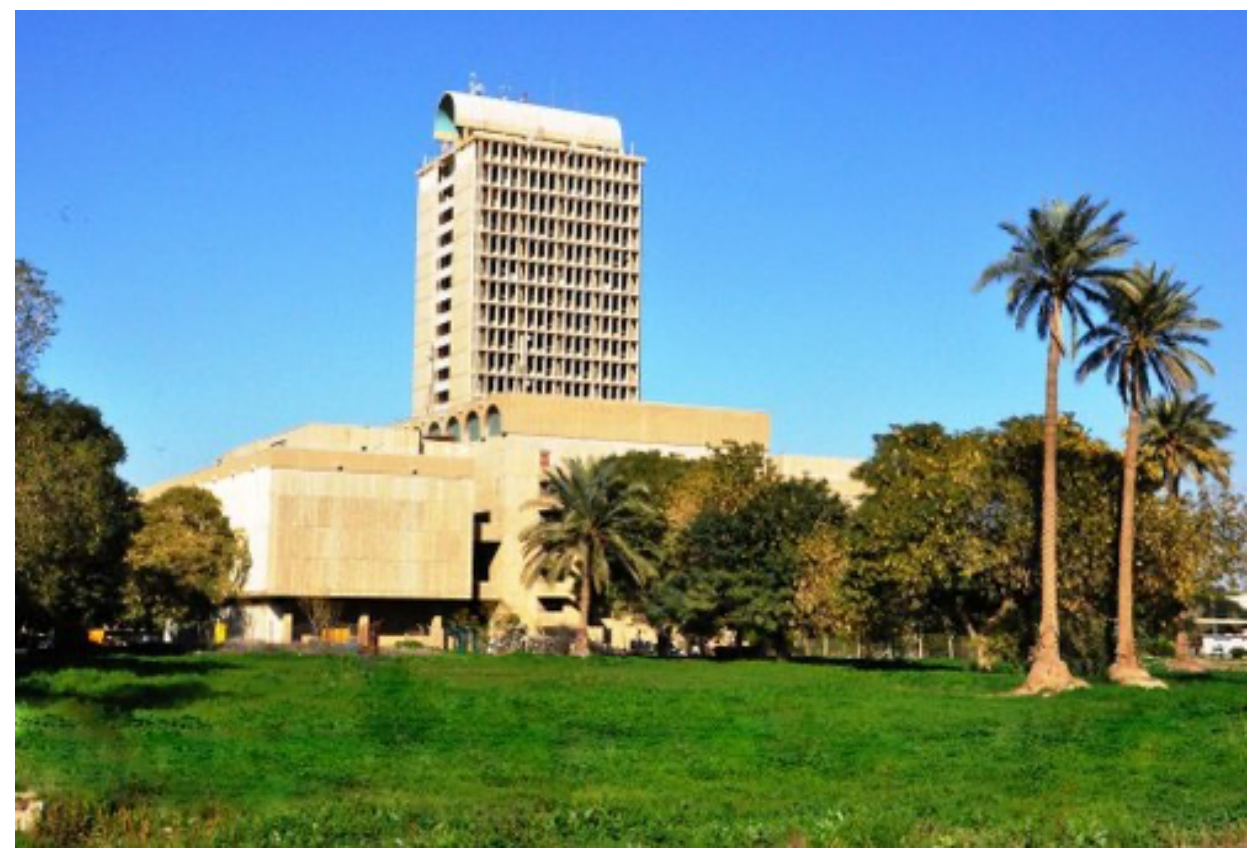

Figure 12. Baghdad University by Walter Gropius, McMillan, Baghdad, Iraq. (https://site.unibo.it/waladu/en/uni-baghdadvteam)

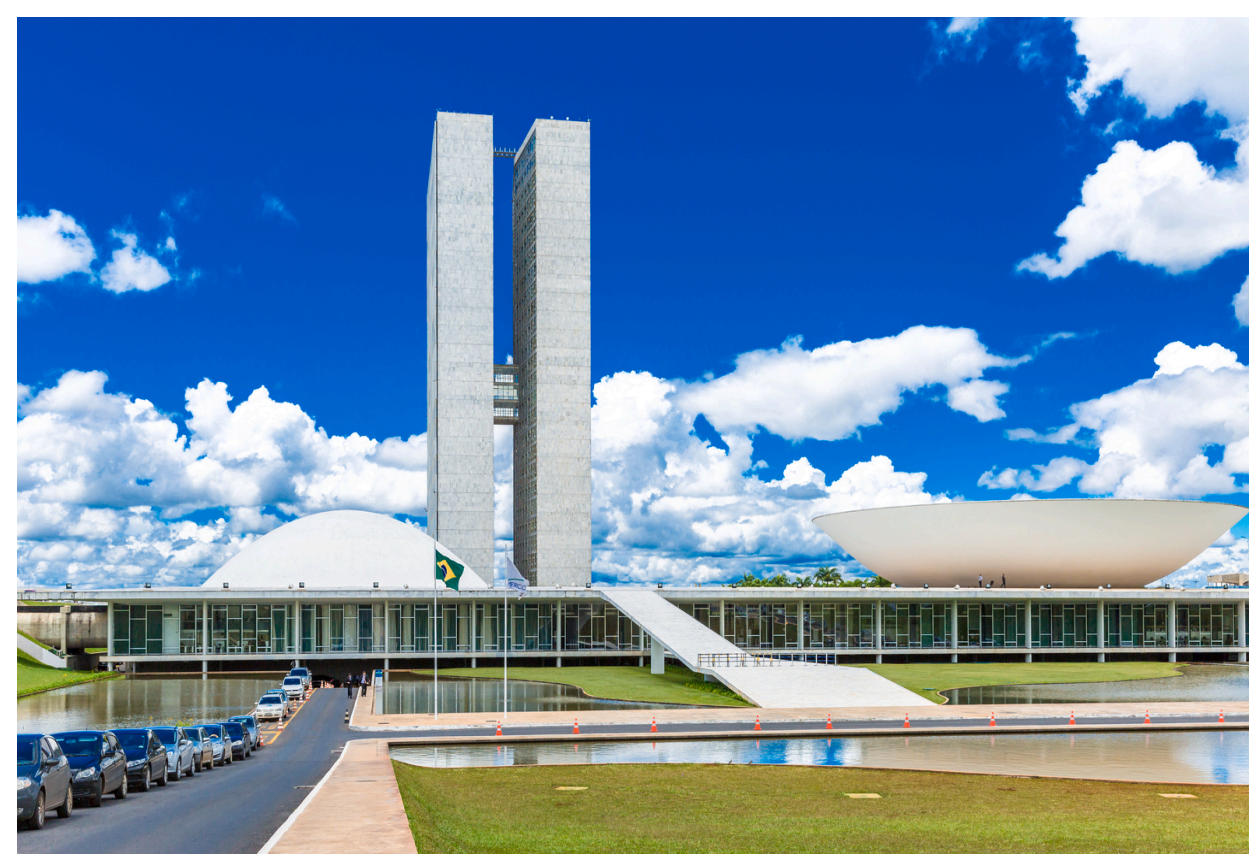

Figure 13. Brazilian parliaments building by Oscar Niemeyer, Brazil.

(https://www.archdaily.com/773568/ad-classics-national-congress-oscar-niemeyer/55f9ba65e58ecec1f800035ead-classics-national-congress-oscar-niemeyer-image) 


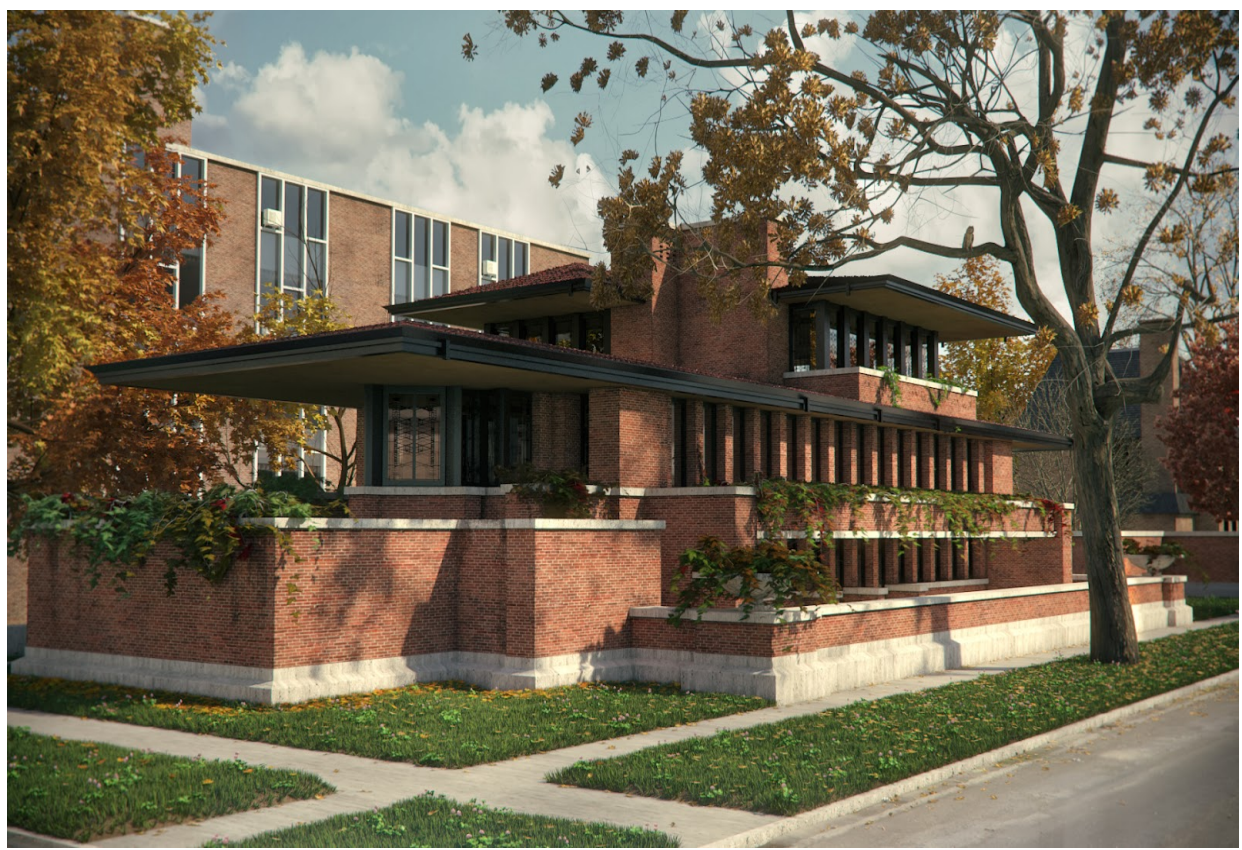

Figure 14. H Robie House by Frank Lloyd Wright, Chicago, USA. (http://2.bp.blogspot.com/-

_kshPPnq6o0/UwGom33ZqGI/AAAAAAAAD9I/aFBgPKflp7U/s1600/robie_house_by_7y8i-d5j8ils.jpg)

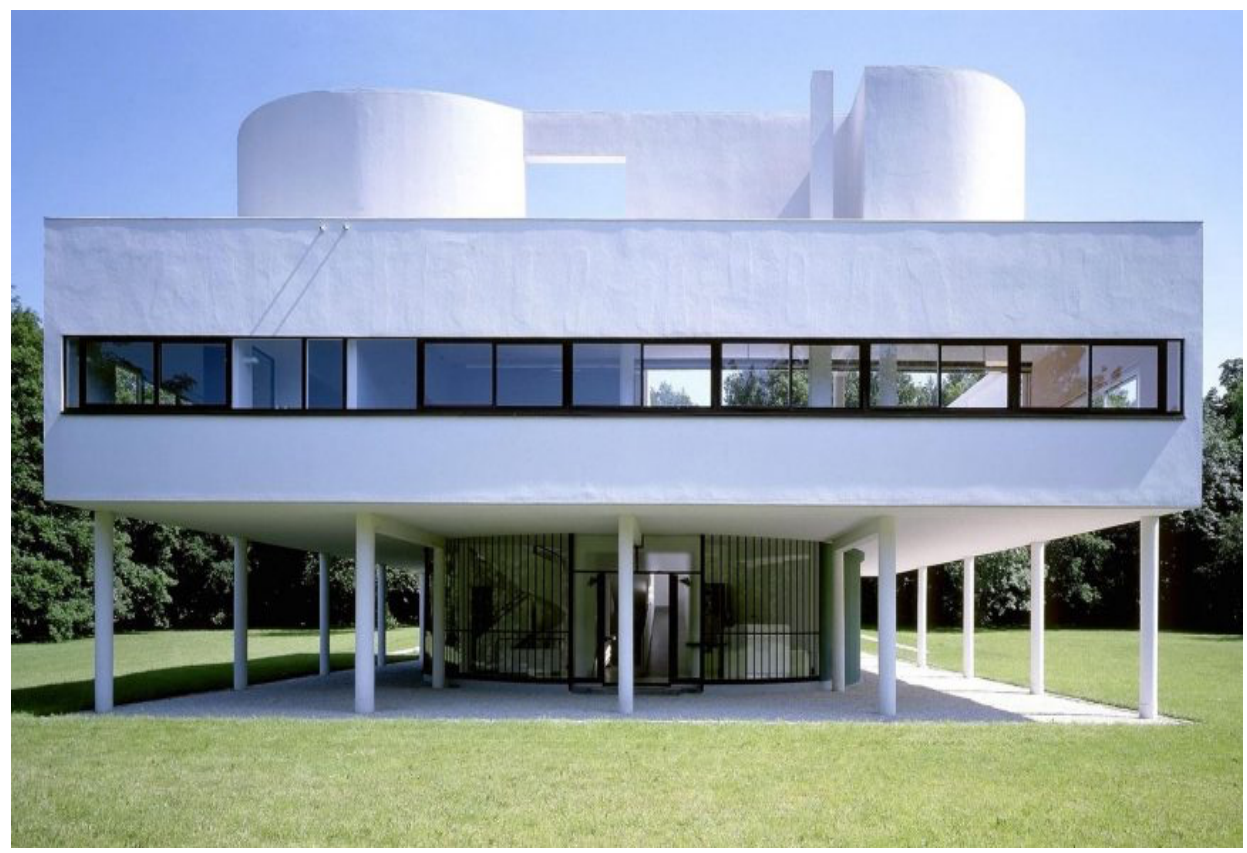

Figure 15. Villa Savoye by le Corbusier, Paris, France.

(https://media.architecturaldigest.in/wp-content/uploads/2018/02/Villa-Savoye-1920x1080-866x487.jpg) 


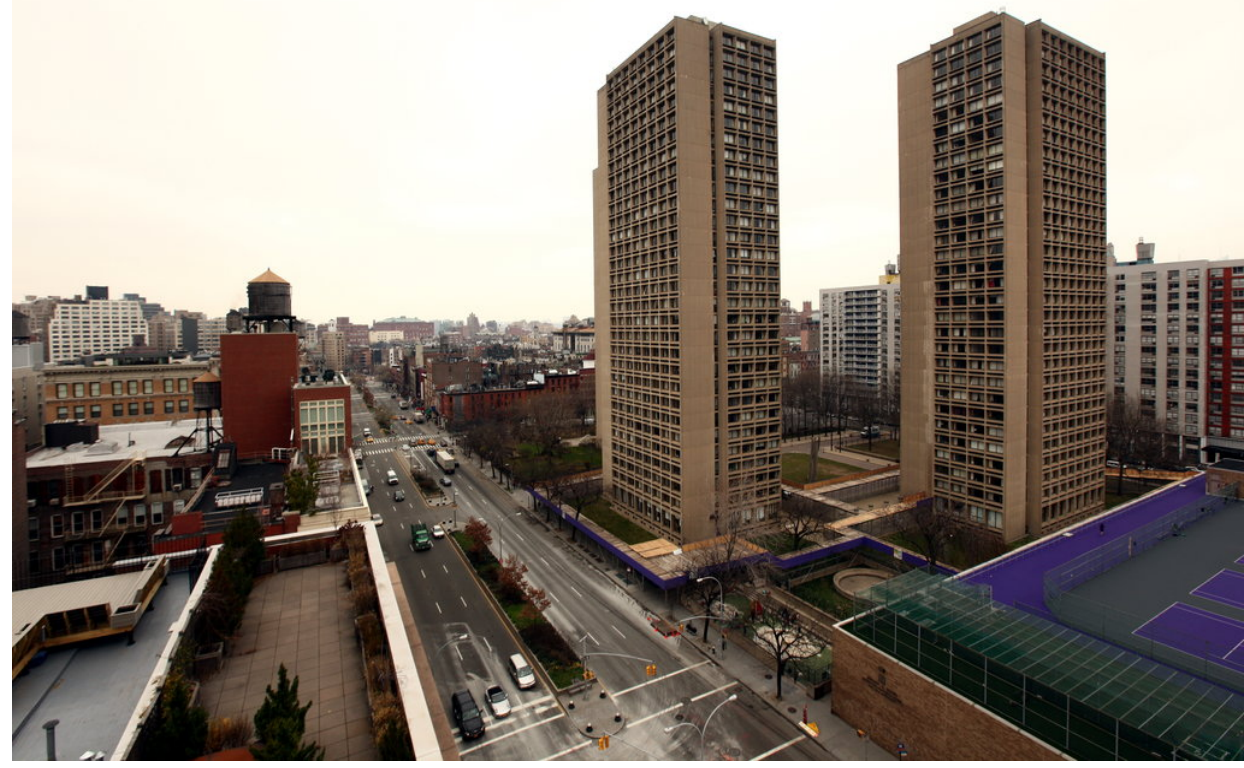

Figure 16. The Silver Towers at New York University by I M Pei, New York, USA. (https://static01.nyt.com/images/2016/01/30/obituaries/16Pei-obit12/IMPei-obituary-slide-CIG7jumbo.jpg?quality $=90 \&$ auto $=$ webp)

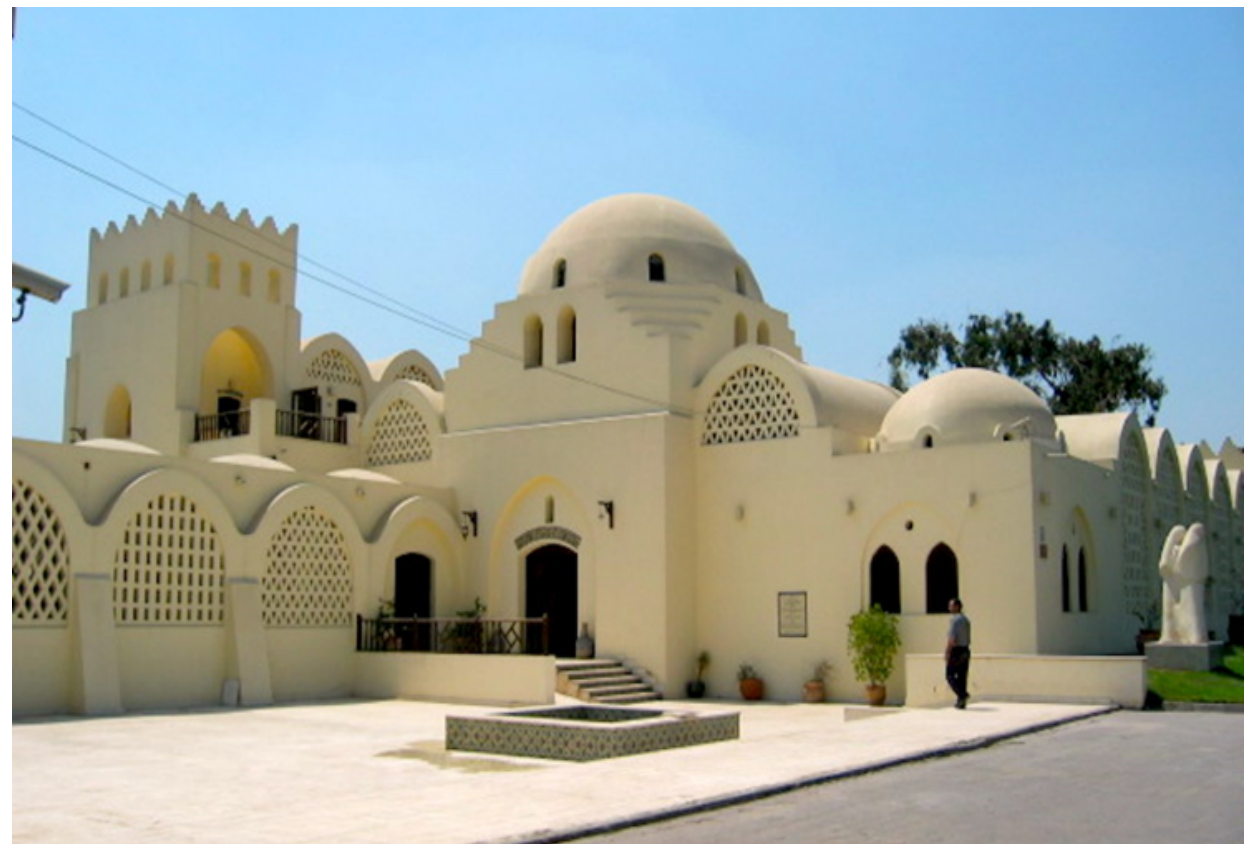

Figure 17. Village of new Gourna by Hasan Fathy, Egypt.

(https://cairoscene.com/ArtsAndCulture/35-Spectacular-Structures-by-Egypt-s-Architectural-Legend-HassanFathy) 


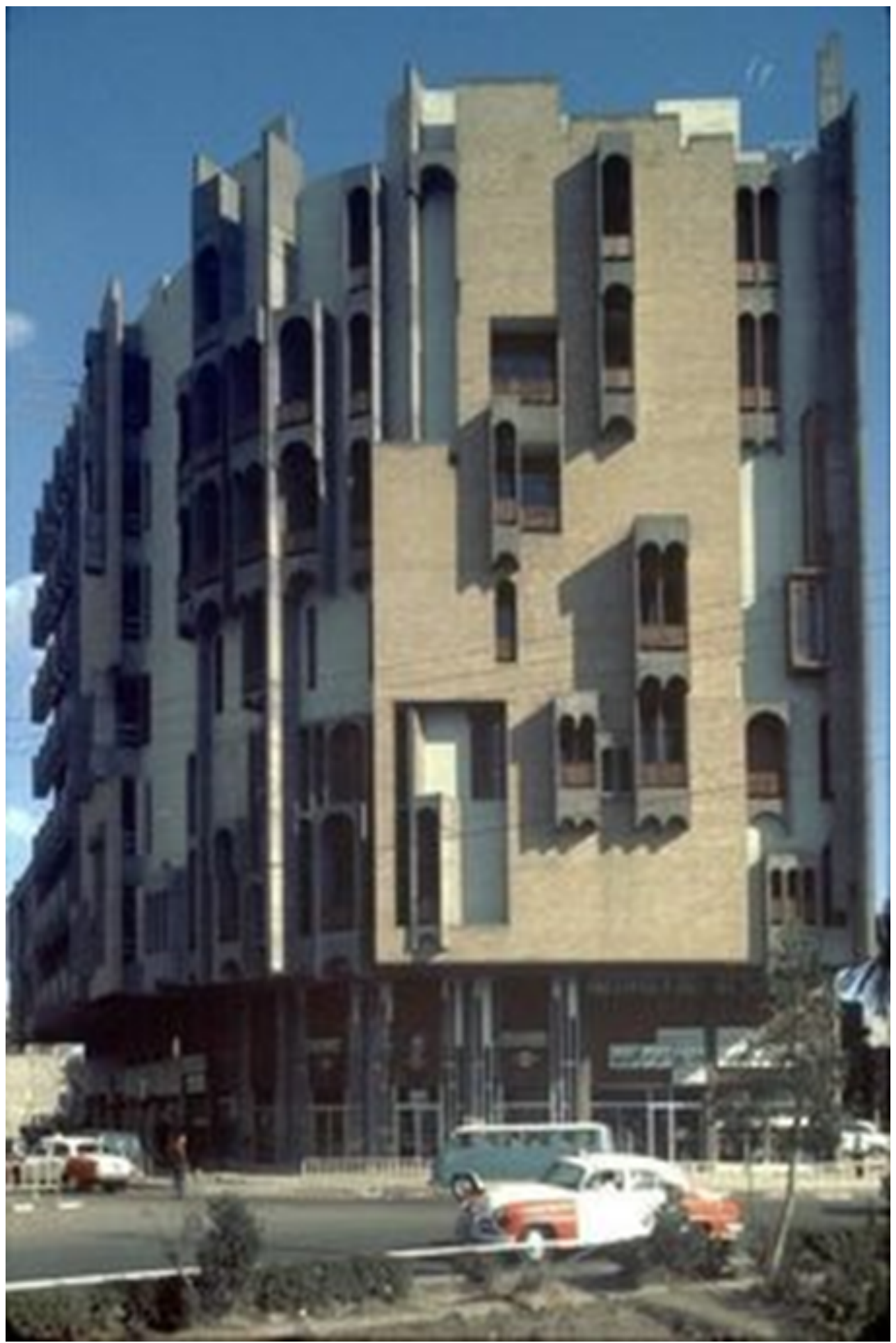

Figure 18. Iraqi federations of industries by Rifat Chadirji, Baghdad, Iraq. (https://i.pinimg.com/236x/cd/f3/50/cdf35093ed224b8fad6ea3a6ad36c971.jpg) 


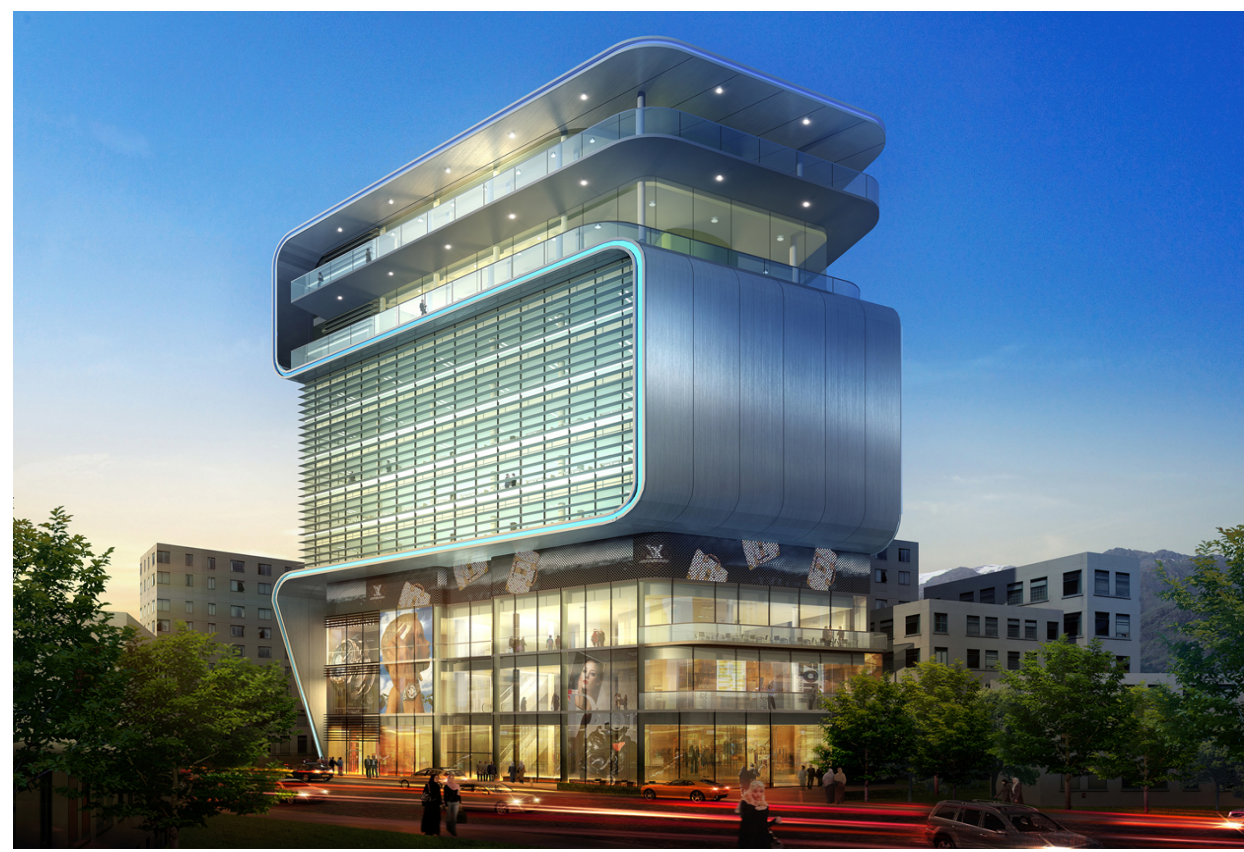

Figure 19. Ribbon of Light, by Tom Wright, Khennouchi and Kuruvilla whilst, Tehran, Iran. (https://wkkarchitects.com/aribbon-of-light-tehran)

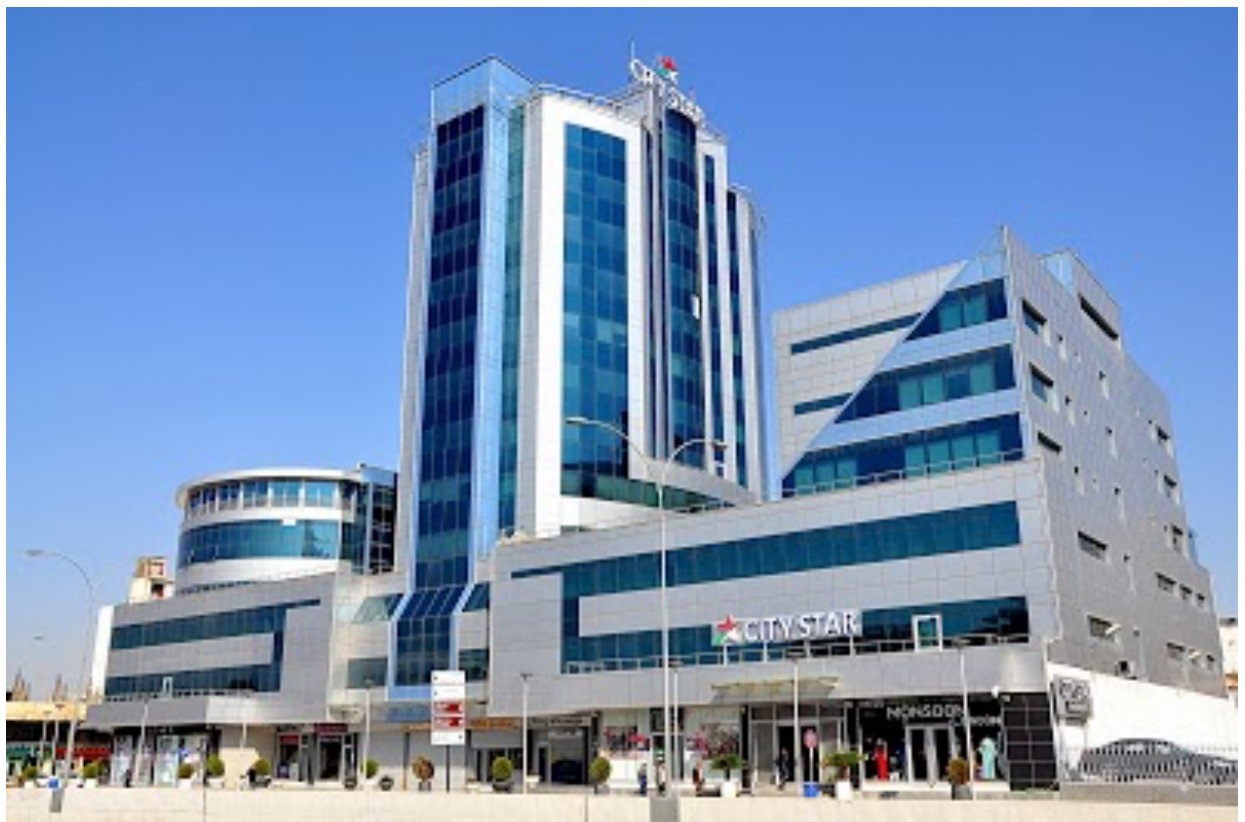

Figure 20. City Star Mall by Niaz Saeed, Sulaymaniyah, Iraq. (https://h3.googleusercontent.com/-

xC9PVoW6Wb8/VwI1amRbA8I/AAAAAAAAAAw/ATt_Zcs8SIoegA1XmZvG5R6ob9JjkE9pQCJkC/s1600w400/) 


\section{RESULTS AND DISCUSSIONS}

Table 1. The grade of ambiguity in boundary limitation of buildings skins compared to other surfaces ambiguity in limitations (A.L.), (Researchers).

\begin{tabular}{|c|c|c|c|c|c|c|c|c|c|c|c|c|}
\hline \multirow{4}{*}{$\dot{0}$} & \multirow{4}{*}{ 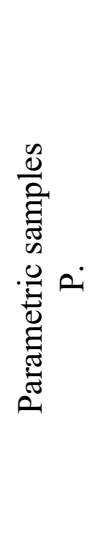 } & \multirow{4}{*}{ 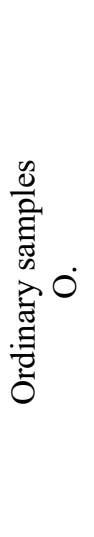 } & \multicolumn{6}{|c|}{ Limitation with } & \multirow{2}{*}{\multicolumn{2}{|c|}{ 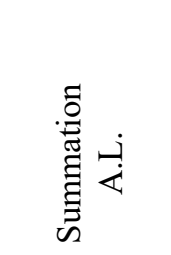 }} & \multirow{2}{*}{\multicolumn{2}{|c|}{ 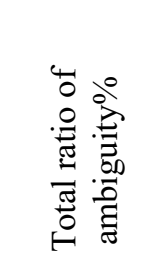 }} \\
\hline & & & \multicolumn{2}{|c|}{ 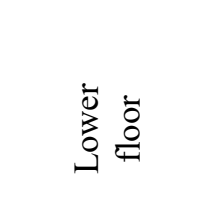 } & \multicolumn{2}{|c|}{$\begin{array}{l}\overline{\mathrm{D}} \\
\stackrel{0}{\circ} \\
\overline{0}\end{array}$} & \multicolumn{2}{|c|}{$\frac{\dot{\theta}}{\tilde{0}} \cdot \frac{\tilde{\theta}}{n}$} & & & & \\
\hline & & & P. & $\mathrm{O}$. & P. & $\mathrm{O}$. & P. & $\mathrm{O}$. & P. & O. & P. & O. \\
\hline & & & $0,1,2$ & $0,1,2$ & $0,1,2$ & $0,1,2$ & $0,1,2$ & $0,1,2$ & 9 & 9 & \multicolumn{2}{|c|}{$\%$} \\
\hline 1 & Fig. 1 & $\begin{array}{c}\text { Fig. } \\
11\end{array}$ & 1 & 0 & 1 & 0 & 1 & 0 & 3 & $\mathbf{0}$ & 33 & $\mathbf{0}$ \\
\hline 2 & Fig. 2 & $\begin{array}{c}\text { Fig. } \\
12\end{array}$ & 2 & 0 & 1 & 0 & 0 & 0 & 3 & $\mathbf{0}$ & 33 & $\mathbf{0}$ \\
\hline 3 & Fig. 3 & $\begin{array}{c}\text { Fig. } \\
13\end{array}$ & 0 & 0 & 0 & 0 & 1 & 0 & 1 & $\mathbf{0}$ & 11 & $\mathbf{0}$ \\
\hline 4 & Fig. 4 & $\begin{array}{c}\text { Fig. } \\
14\end{array}$ & 2 & 0 & 2 & 0 & 2 & 0 & 6 & $\mathbf{0}$ & 67 & $\mathbf{0}$ \\
\hline 5 & Fig. 5 & $\begin{array}{c}\text { Fig. } \\
15\end{array}$ & 1 & 0 & 1 & 0 & 1 & 0 & 3 & $\mathbf{0}$ & 33 & $\mathbf{0}$ \\
\hline 6 & Fig. 6 & $\begin{array}{c}\text { Fig. } \\
16\end{array}$ & 2 & 0 & 2 & 0 & 2 & 0 & 6 & $\mathbf{0}$ & 67 & $\mathbf{0}$ \\
\hline 7 & Fig. 7 & $\begin{array}{c}\text { Fig. } \\
17\end{array}$ & 1 & 0 & 1 & 0 & 1 & 0 & 3 & $\mathbf{0}$ & 33 & $\mathbf{0}$ \\
\hline 8 & Fig. 8 & $\begin{array}{c}\text { Fig. } \\
18\end{array}$ & 0 & 0 & 0 & 0 & 0 & 0 & $\mathbf{0}$ & $\mathbf{0}$ & $\mathbf{0}$ & $\mathbf{0}$ \\
\hline 9 & Fig. 9 & $\begin{array}{c}\text { Fig. } \\
19\end{array}$ & 1 & 0 & 0 & 0 & 1 & 0 & 2 & 0 & 22 & 0 \\
\hline 10 & $\begin{array}{c}\text { Fig. } \\
10\end{array}$ & $\begin{array}{c}\text { Fig. } \\
20\end{array}$ & 2 & 0 & 2 & 0 & 2 & 0 & 6 & 0 & 67 & 0 \\
\hline$\%$ & & & 40 & 0 & 33 & 0 & 37 & 0 & 37 & $\mathbf{0}$ & 37 & $\mathbf{0}$ \\
\hline
\end{tabular}




\section{Content of Table 1}

The research represents Figures from 1 to 10 in the second column beside the Figures 11-20 in the third column. After that, there are three sub categories of architectural skin's limitation with (lower floor, upper floor, and other vertical surfaces). For each category, there are three grades $(0,1$, and 2$)$ depending on limitation ambiguity, which means that there are 9 different grades for each example.

According to the results of Table 1,the research found that the ratios of ambiguity in architectural skin's boundaries limitation are as follows.

- In general, parametric skins have a medium values, between 0 and 67 percent for each sample, $\% 37$ in average, totally.

- In general, ordinary skins have the lowest value, (0) percent for all samples, $0 \%$ totally.

- Figures 4, 6, and 10 have the highest value, 67\% of ambiguity in architectural skin's boundaries limitation.

- $\quad$ Figure 8 has the lowest value, $0 \%$.

- Total skin limitation for P. samples is $40 \%$ with lower floor, $33 \%$ with upper floor, and $37 \%$ with other vertical surfaces.

- All skin limitations for O. samples with lower floor, upper floor, and with other vertical sides were $0 \%$.

- Generally, whenever architectural skin designed in parametric way it loses some of its essence, which is boundary limitations clearness.

\section{CONCLUSION}

From the discussions, the following is noticed.

- $\quad$ The medium range of ambiguity limitation of architectural skin of buildings designed with parametric confirms the hypothesis of the research, meaning lack of clear boundary, on contrary to the result that there is no ambiguity limitation of architectural skin of buildings designed ordinary, which means a clear boundary with the other surfaces.

- Parametric architectural skins have a high ratio of ambiguity limitation with lower floors compared to their limitation with other sides, while ambiguity limitation with the upper floor has the lowest ratio within parametric samples.

- Parametric architectural skin lost a part of its essence due to loosing the property of having a specific and clear boundary limitation.

- Parametric architectural skin lost a part of its role in forming and representing the architectural form.

- Discovering the fact that architectural skin's essence was changed leads to observing the emergence of new essence for it.

- Changes in the role and essence of skins lead to changes in designed process. Other essence of skins deserves studying in the future. There are also new characters that may receive a great role in forming and representing architectural form. 


\section{REFERENCES}

Baker, John Milnes, A.I.A. 1994. American House Styles: A Concise Guide, Norton.

Bottazzi, Roberto. 2018. Digital Architecture Beyond Computers Fragments of a Cultural History of Computational Design.

Caetano, Inês and others. 2020. Computational design in architecture: Defining parametric, generative, and algorithmic design.

Gallas, Mohamed-Anis \& others. 2015. Parametric Modeling, An Advanced Design Process for Architectural Education, CAAD Education - Tools - Volume 2 - CAAD 33.

Graham, Peter C. 2012. The Parametric Façade Optimization in Architecture through a Synthesis of Design, Analysis and Fabrication, University of Waterloo, Ontario, Canada.

Kelly, T. 2013.Unwritten Procedural Modeling with Skeletons, Ph.D. Thesis, University of Glasgow.

Nonko, Emily. 2016. A Guide to Architect Terms and Phrases.

(https://www.curbed.com/2016/7/11/12149096/architecture-glossary-architect-terms)

Pell, Ben. 2010. The articulate surface, ornament and technology in contemporary architecture, Birkhauser.

Schnabel, Marc Aurel, 2007, Computer-Aided Architectural Design (CAADfutures)

Schodek, Daniel L. 2005. Digital Design and Manufacturing, CAD Hoboken, John Wiley.

Schumacher, Patrik. 2016.Parametricism 2.0: Rethinking Architecture's Agenda for the 21st Century, Architectural Design, 2nd vol. 86. Chichester: Wiley and Son.

Stals, Adeline and others. 2021. Parametric modeling tools in small architectural offices: Towards an adapted design process model,Design Studies, Volume 72.

Terzidis, Kostas. 2003.Expressive Form, A Conceptual Approach to Computational Design, Spon Press, New York.

Woodbury, Robert. 2010. Elements of parametric design, Routledge, New York.

Sung, Yuchen Sharon \& Tseng, Yingjui, 2016. Parametric Models of Facade Designs of High-Rise Residential Buildings, IACSIT International Journal of Engineering and Technology, Vol. 8, No. 4, August.

Zarei, Yasser. 2012. The Challenges of Parametric Design in Architecture Today, Mapping the Design Practice, The University of Manchester for (MPhil) in the Faculty of Humanities, School of Environment and Development. 